\title{
Study on Mechanical Properties of Recycled Mixture with High Content of Iron Tailings Sand
}

\author{
Yuanshuai Dong, ${ }^{1,2,3}$ Hong Zhang $\mathbb{D}^{1}{ }^{1}$ Yun Hou, ${ }^{2,3}$ Zhenyu Qian, ${ }^{2,3}$ and Jialei Tian $\mathbb{D}^{2,3}$ \\ ${ }^{1}$ Department of Civil Engineering, Chongqing Jiaotong University, Chongqing 400047, China \\ ${ }^{2}$ China Highway Engineering Consulting Corporation, Beijing 100089, China \\ ${ }^{3}$ Highway Construction and Maintenance Technology, \\ Materials and Equipment Transportation Industry Research and Development Center, Beijing 100089, China
}

Correspondence should be addressed to Hong Zhang; zh1223021307@163.com and Jialei Tian; tianjialei99@126.com

Received 18 August 2021; Revised 15 October 2021; Accepted 18 October 2021; Published 31 October 2021

Academic Editor: Meng Guo

Copyright (c) 2021 Yuanshuai Dong et al. This is an open access article distributed under the Creative Commons Attribution License, which permits unrestricted use, distribution, and reproduction in any medium, provided the original work is properly cited.

\begin{abstract}
This paper focuses on the disposal of iron tailings sand (ITS) and reclaimed inorganic binder stabilized aggregate (RAI), and a new "ITS plus RAI" solid waste treatment method is innovatively proposed, which uses ITS and RAI as a new base course material to replace of new aggregates by $100 \%$. It is found that the new ITS and RAI mixture has excellent compressive performance by designing the material composition of the mixture, which can meet the design strength of different levels of pavement under various load conditions. A series of laboratory tests are used to study the effect of the content of special cementitious material and iron tailings on the uniaxial compressive strength, flexural-tensile strength, compressive resilience modulus, and flexural-tensile resilience modulus of recycled mixture. And, the scanning electron microscope test (SEM) and X-ray diffraction test (XRD) are used to compare the surface morphology characteristics and hydration products of the recycled mixture under different ratios and to discuss the formation mechanism of the strength of the mixture. The test results show that the macroscopic change pattern in laboratory tests is basically consistent with the results in microanalysis. The relationship between compressive strength and compressive resilience modulus and flexural resilience modulus is also established by linear regression. This solid waste treatment method is applied to the pavement renovation project of national and provincial roads in Shanxi Province (within Linfen), to replace the existing base material by using recycled mixture, and the results show that it can save not only the carbon emission from stone mining and processing but also the construction cost, while producing good social and economic benefits and promoting the process of carbon neutralization in the world.
\end{abstract}

\section{Introduction}

In recent years, the concept of sustainable development is deeply rooted among the people. The recycling of solid industrial waste as engineering materials can not only effectively dispose the solid waste but also save social resources and protect the ecological environment, which is currently one of the research hotspots that engineers and technicians all over the world are committed to promoting. ITS is the grain size less than $4.75 \mathrm{~mm}$ produced by iron ore after grinding and sorting. Iron tailings sand is the main component of industrial solid waste; for example, in China, there are nearly 2 billion tons of iron tailings sands in existence and the annual discharge is over 75 million tons; the large quantity iron tailings sand not only occupies land and pollutes the environment but also has great safety risks [1].

Many scholars are devoted to the application of ITS in engineering materials and have achieved a large number of results, among which the proportion of studies on the use of ITS in cement concrete is larger. In contrast, there is less research on ITS in pavement base or subgrade filler. Although some existing studies [2-10] have a comprehensive research on the strength formation mechanism, mechanical properties, and road performance of cement-stabilized ITS, however, most studies only focus on the feasibility of the mixture from pavement performance, while ignoring the 
study of micromechanism. Coupled with the grading limits of current design codes, the ITS has a low substitution rate for fine aggregate in the base course, which restricts the utilization rate of ITS.

Meanwhile, a large amount of RAI are generated from maintenance and reconstruction works of the pavement every year, and the raw RAI is generally used as subgrade filler or the base course and subbase of low-grade pavement, or even directly discarded; thus, all of these treatments brought a low addition value to RAI [11]. There are a lot of micron-sized cement hydrate particles on the surface of RAI, which will affect the strength, cracking resistance, and durability of the recycled mixture [12, 13]. Physical and chemical measures can effectively improve its properties, while the engineering application is complex and difficult [11].

In summary, it is feasible to, respectively, use ITS and RAI as the pavement base course, while the content is generally low, and there is no precedent to use both two materials simultaneously. This paper aimed at "ITS plus RAI" solid waste treatment technology, which replaces $100 \%$ of natural aggregates with ITS and RAI as pavement base course material. It can reduce carbon emission and promote the green, high efficiency, high quality, high value, and scale utilization of ITS, can improve the utilization level of ITS, and help the ecological civilization. This paper investigated the strength formation mechanism of recycled mixtures, the hydration products of the mixture in microscale are analyzed by using SEM and XRD test, and the mechanical properties of the mixtures in macroscale are analyzed by using unconfined compressive strength and flexural strength test.

\section{Materials and Material Composition Design}

This study intends to maximize the utilization rate of ITS on the premise of meeting the strength design requirements of semirigid base material, and relevant studies have already designed the mixture for stabilized ITS with natural aggregates [14]. Therefore, the test selected ITS and RAI blending ratio of 50\%:50\%, 60\%: $40 \%$, and 70\%: $30 \%$, respectively, cementitious material (external) blending $4 \%$, $6 \%, 8 \%$, and $10 \%$ of the ratio. Considering that the recycled mixture belongs to the inorganic bonding material, the compaction test and unconfined compressive strength test in this section refer to the relevant test requirements of the Test Methods of Materials Stabilized with Inorganic Binders for Highway Engineering (JTG E51-2009).

\subsection{Materials}

2.1.1. ITS. ITS is retrieved from Xianfen County, Linfen City, Shanxi Province. The selected ITS is extra fine sand with good cleanliness and negligible content of harmful metal elements below $0.01 \%$, which will not cause pollution to the environment or water bodies. The screening result and basic physical properties are shown in Tables 1 and 2 .
2.1.2. RAI. The RAI used in this study are selected from the recycled material of the base course of Linxia section of the provincial pavement in Linfen City, Shanxi Province. 56.2\% of the coarse aggregate and the measured crushing value of $10-15 \mathrm{~mm}$ reach $25.8 \%$, and the sand equivalent of the fine aggregate of the RAI reaches $75 \%$, with a great degree of cleanliness, which is conducive to the bonding of the cementitious material with the aggregate. The screening result of the RAI is shown in Table 3.

2.1.3. Cementitious Material. The cementitious material, from Nanjing Runcheng Engineering Consulting Co., Ltd., is mainly composed of calcium oxide $(\mathrm{CaO})$ and silicon dioxide $\left(\mathrm{SiO}_{2}\right)$, whose basic physical properties and main components are shown in Tables 4 and 5.

\subsection{Material Composition Design}

2.2.1. Heavy Compaction Test. In this study, a heavy compaction test is used to determine the optimum water content and maximum dry density of the recycled mixture; according to the Test Methods of Materials Stabilized with Inorganic Binders for Highway Engineering T 0804-1994 (JTG E51 -2009), the compaction test apparatus is shown in Figure 1, the hammer weight is $4.5 \mathrm{~kg}$, the drop distance is $45 \mathrm{~cm}$, and the compaction is done in three layers and the number of times each layer is 98 . The compaction test results for different designs of recycled mixtures are shown in Table 6.

The test results show that the maximum dry density of the recycled mixture tends to rise with the increase of cementitious material admixture under the same amount of ITS and the optimum water content is stable between $8.5 \%$ and $9.5 \%$. And, the optimum water content and maximum dry density decrease, with the increase of ITS admixture under the same amount of cementitious material, is mainly caused by the water absorption rate and density of ITS and RAI.

2.2.2. Unconfined Compressive Strength Test. Based on the results of the compaction test, $150 \mathrm{~mm} * 150 \mathrm{~mm}$ cylindrical specimens are formed under the optimum water content by $2000 \mathrm{kN}$ Press Machine (Figure 2) at a loading speed of $10 \mathrm{~mm} / \mathrm{min}$, raising in a standard room at a temperature of $20 \pm 2^{\circ} \mathrm{C}$ and relative humidity of $95 \%$ or more for 6 days; after immersing in water for 24 hours, wipe the water on the surface with a damp cloth to determine its unconfined compressive strength by pavement material strength tester (Figure 3 ) at a loading speed of $1 \mathrm{~mm} / \mathrm{min}$. The results of the $7 \mathrm{~d}$ unconfined compressive strength test of the recycled mixture are shown in Figure 4.

The test results show that the recycled mixture has good compressive strength. In the same ITS content, the compressive strength increases with the increase of the cementitious material content; in the same cementitious material content, the compressive strength decreases with the increase of the ITS content. Mainly because when the 
TABLE 1: ITS gradation.

\begin{tabular}{lccccccc}
\hline Sieve size $(\mathrm{mm})$ & 4.75 & 2.36 & 1.18 & 0.6 & 0.3 & 0.15 & 0.075 \\
\hline Pass-rate $(\%)$ & 100 & 99.8 & 98 & 90.4 & 60.2 & 35.8 & 13.2 \\
\hline
\end{tabular}

TABLE 2: Technical indexes of ITS.

\begin{tabular}{lcccccccc}
\hline $\begin{array}{l}\text { Fineness } \\
\text { modulus }\end{array}$ & $\begin{array}{c}\text { Water content } \\
(\%)\end{array}$ & $\begin{array}{c}\text { Apparent density }(\mathrm{g} / \\
\left.\mathrm{cm}^{3}\right)\end{array}$ & $\begin{array}{c}\text { Water absorption } \\
(\%)\end{array}$ & $\begin{array}{c}\text { Sand equivalent } \\
(\%)\end{array}$ & $\begin{array}{c}\mathrm{SiO}_{2} \\
(\%)\end{array}$ & $\begin{array}{c}\mathrm{CaO} \\
(\%)\end{array}$ & $\begin{array}{c}\mathrm{Cr}(\%) \\
(\%)\end{array}$ \\
\hline 1.1 & 8.2 & 2.99 & 3.7 & 82 & 41.01 & 24.35 & 0.004 & 0.001 \\
\hline
\end{tabular}

TABLE 3: RAI gradation.

\begin{tabular}{lcccccc}
\hline Sieve size $(\mathrm{mm})$ & 26.5 & 19 & 16 & 13.2 & 9.5 & \\
\hline Pass rate $(\%)$ & 100 & 97.0 & 92.2 & 86.9 & 63.7 & 43.8 \\
Sieve size $(\mathrm{mm})$ & 2.36 & 1.18 & 0.6 & 0.3 & 0.15 & 0.075 \\
Pass rate $(\%)$ & 23.2 & 14.5 & 7.7 & 3.3 & 1.4 & 0.5 \\
\hline
\end{tabular}

TABLe 4: Technical indexes of special cementitious material.

\begin{tabular}{lccccccc}
\hline & & \multicolumn{2}{c}{$\begin{array}{c}\text { Setting time } \\
(\mathrm{min})\end{array}$} & \multicolumn{2}{c}{ Strength of $7 \mathrm{~d}(\mathrm{MPa})$} & \multicolumn{2}{c}{ Strength of $28 \mathrm{~d}(\mathrm{MPa})$} \\
$\begin{array}{l}\text { Apparent density } \\
\left(\mathrm{g} / \mathrm{cm}^{3}\right)\end{array}$ & $\begin{array}{c}\text { Specific surface area } \\
\left(\mathrm{m}^{2} / \mathrm{kg}\right)\end{array}$ & $\begin{array}{c}\text { Initial } \\
\text { set }\end{array}$ & $\begin{array}{c}\text { Final } \\
\text { set }\end{array}$ & $\begin{array}{c}\text { Compressive } \\
\text { strength }\end{array}$ & $\begin{array}{c}\text { Rupture } \\
\text { strength }\end{array}$ & $\begin{array}{c}\text { Compressive } \\
\text { strength }\end{array}$ & $\begin{array}{c}\text { Rupture } \\
\text { strength }\end{array}$ \\
\hline 2.85 & 350 & 246 & 531 & 31.9 & 6.7 & 61.2 & 8.8 \\
\hline
\end{tabular}

TABLE 5: Main compositions of special cementitious material.

\begin{tabular}{lccccccccc}
\hline Items & $\mathrm{CaO}$ & $\mathrm{Si}_{2} \mathrm{O}$ & $\mathrm{Al}_{2} \mathrm{O}_{3}$ & $\mathrm{MgO}$ & $\mathrm{SO}_{3}$ & $\mathrm{Fe}_{2} \mathrm{O}_{3}$ & $\mathrm{~K}_{2} \mathrm{O}$ & $\mathrm{TiO}_{2}$ & $\mathrm{Na}_{2} \mathrm{O}$ \\
\hline Rate $\%$ & 39.98 & 27.67 & 13 & 7.656 & 2.55 & 0.69 & 0.525 & 0.517 & 0.422 \\
\hline
\end{tabular}

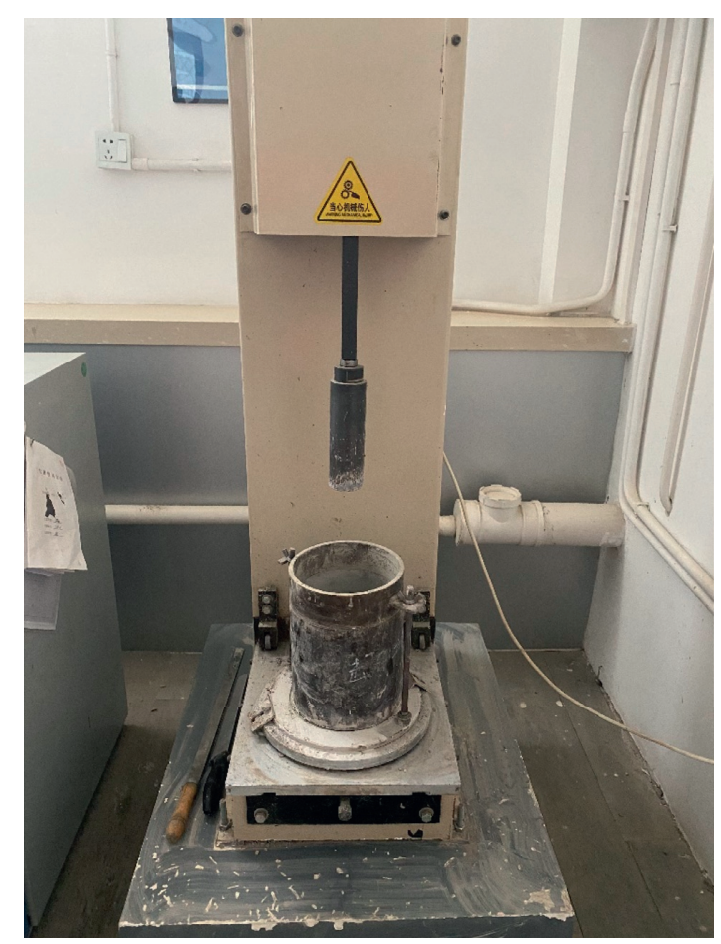

Figure 1: Compaction test apparatus. 
TABle 6: Compaction test results.

\begin{tabular}{lccccccc}
\hline \multirow{2}{*}{ Mixture proportion } & \multicolumn{3}{c}{ Optimum water content $(\%)$} & \multicolumn{4}{c}{ Maximum dry density $\left(\mathrm{g} / \mathrm{cm}^{3}\right)$} \\
& 4 & 6 & 8 & 10 & 4 & 6 & 8 \\
\hline $50 \%: 50 \%$ & 9.0 & 9.3 & 9.4 & 9.4 & 2.109 & 2.117 & 2.128 \\
$60 \%: 40 \%$ & 8.9 & 9.2 & 9.1 & 9.1 & 2.083 & 2.089 & 2.100 \\
$70 \%: 30 \%$ & 8.8 & 8.9 & 8.8 & 9.0 & 2.072 & 2.073 & 2.132 \\
\hline
\end{tabular}

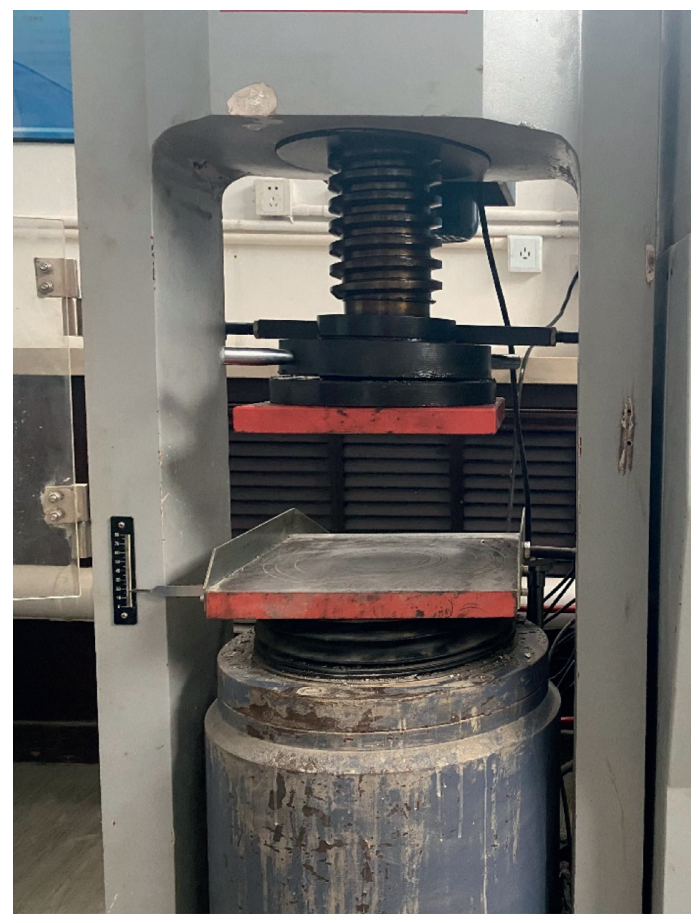

FIgURE 2: $2000 \mathrm{kN}$ press machine.

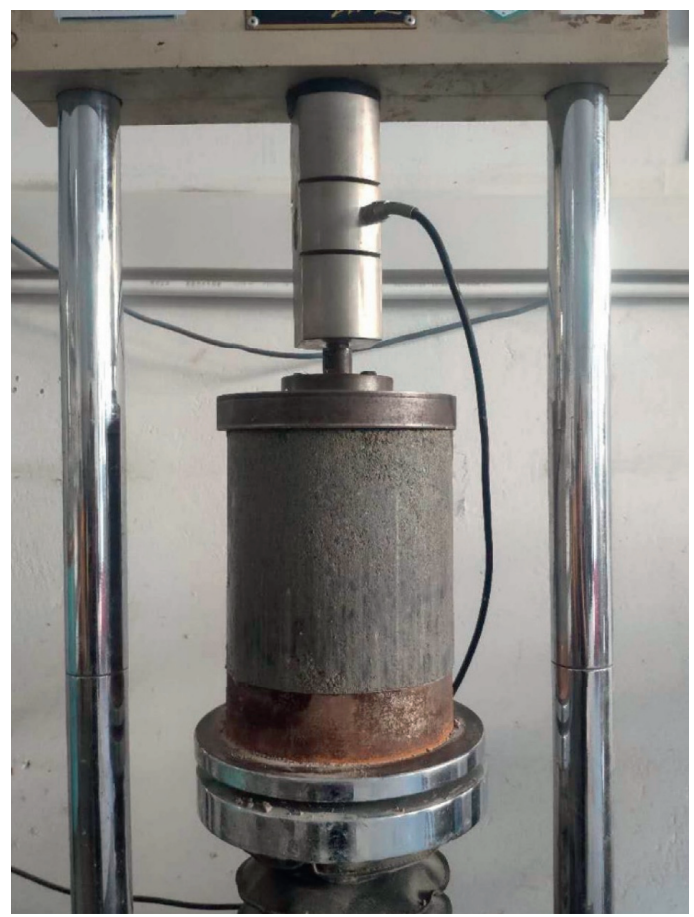

Figure 3: Pavement material strength tester. 


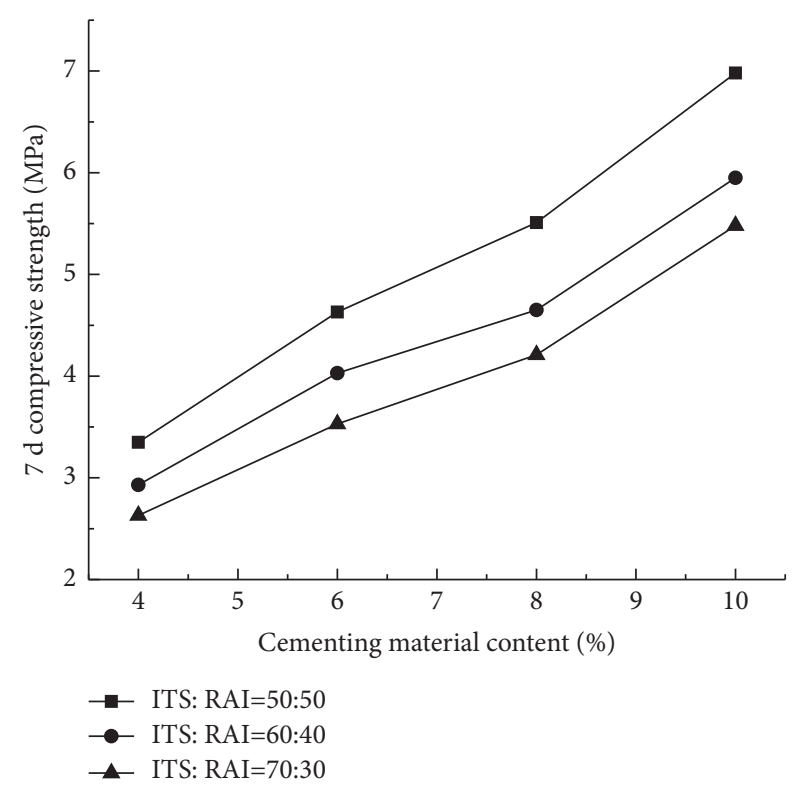

Figure 4: $7 \mathrm{~d}$ compressive strength test results.

hydration product is certain, the higher the amount of ITS is, the finer the particles are and the more difficult to form a stable whole. At the same time, the reduction of RAI reduces the skeletal support, which is also one of the reasons for the reduction in strength. The compressive strength of the recycled mixture can be up to $7 \mathrm{MPa}$, which can meet the design strength requirements of different levels of pavements under various load conditions. However, the higher the strength, the more likely to produce the cracking problem, so the design should be a reasonable choice of the content of cementitious materials.

\section{Mechanical Properties Test and Results Analysis}

According to material design composition, the mechanical properties of the recycled mixture of different ratios are tested and compared with commonly used materials stabilized with inorganic binders to evaluate the mechanical properties of the recycled mixture. And, through linear fitting analysis, the relationship between strength and rebound modulus is established.

3.1. Compressive Strength. Figure 5 shows the unconfined compressive strength test results for the recycled mixture at the age of $3,7,14,28$, and $90 \mathrm{~d}$ at $8 \%$ cementitious material dosage. The following conclusions can be drawn from the analysis of the test results.

(1) From Figure 5, the test results show that the compressive strength of the recycled mixture grows fastest from $3 \mathrm{~d}$ to $7 \mathrm{~d}$. After $28 \mathrm{~d}$, the trend of strength growth slows down gradually, and the compressive strength of the three ratios of the recycled mixture at $7 \mathrm{~d}$ all reaches about $80 \%$ at $90 \mathrm{~d}$. It indicates that the cementitious material can promote the rapid formation of the early strength of the recycled mixture.

(2) Combined with Figures 4 and 5, we can see that the compressive strength of the recycled mixture can reach $7 \mathrm{MPa}$ which has good compressive properties, through the adjustment of material composition, which can meet the design strength requirements of different levels of pavements under various load conditions and has good compressive properties.

3.2. Flexural-Tensile Strength. At present, with the increasing traffic volume, the base course materials not only need high compressive strength but also need good tensile strength. And, the real force state of the pavement is closer to the flexural-tensile state, so this paper uses flexural-tensile strength to analyze the tensile performance of the recycled mixture. Combined with Section 2.2.2, the flexural-tensile strength of five different blending ratios (which can meet the $7 \mathrm{~d}$ unconfined compressive strength requirements of highgrade pavements) is analyzed to explore the influences of the number of cementitious materials and ITS on the flexuraltensile strength of the recycled mixture.

According to the Test Methods of Materials Stabilized with Inorganic Binders for Highway Engineering (JTG E512009), $100 * 100 * 400 \mathrm{~mm}$ medium beam specimens (Figure 6) are formed by the hydrostatic method under the $\mathrm{OWC}$, with the pressure rate of $5 \mathrm{~mm} / \mathrm{min}$. The flexuraltensile strength of the recycled mixture is tested (Figure 7) after different ages $(28 \mathrm{~d}, 90 \mathrm{~d}$, and $180 \mathrm{~d})$ of regeneration under standard conditions, and the test rate is $50 \mathrm{~mm} / \mathrm{min}$. The test results are shown in Figure 8, and the analysis of the test results can be concluded as follows.

(1) In the same ITS content, the flexural-tensile strength increases with the increase of the cementitious material content; in the same cementitious material content, the strength decreases with the increase of the ITS content, which is the same as the regular pattern of compressive strength.

(2) It is calculated that the $28 \mathrm{~d}$ flexural-tensile strength of recycled mixture at studied ratios is $70 \%-80 \%$ of the $180 \mathrm{~d}$ strength. And, the later strength growth trend is larger when the ITS is lower, which may be due to the low amount of ITS. The specific surface area of the recycled mixture is small, and the surplus of cementitious material consumed in the early formation of strength is relatively more. Thus, the hydration reaction can occur continuously in the later stage to promote the formation of strength. The flexural-tensile strength increases about $20 \%$ for every $2 \%$ increase in the amount of cementitious material under $50 \%$ ITS content. When the amount of cementitious material is $8 \%$, the flexural-tensile strength decreases about $10 \%$ for every $10 \%$ increase in the amount of ITS. So, the influence of cementitious material on the recycled mixture is greater.

(3) Compared with the $90 \mathrm{~d}$ flexural-tensile strength (0.9-2.0 MPa) of cement-stabilized aggregates in the 


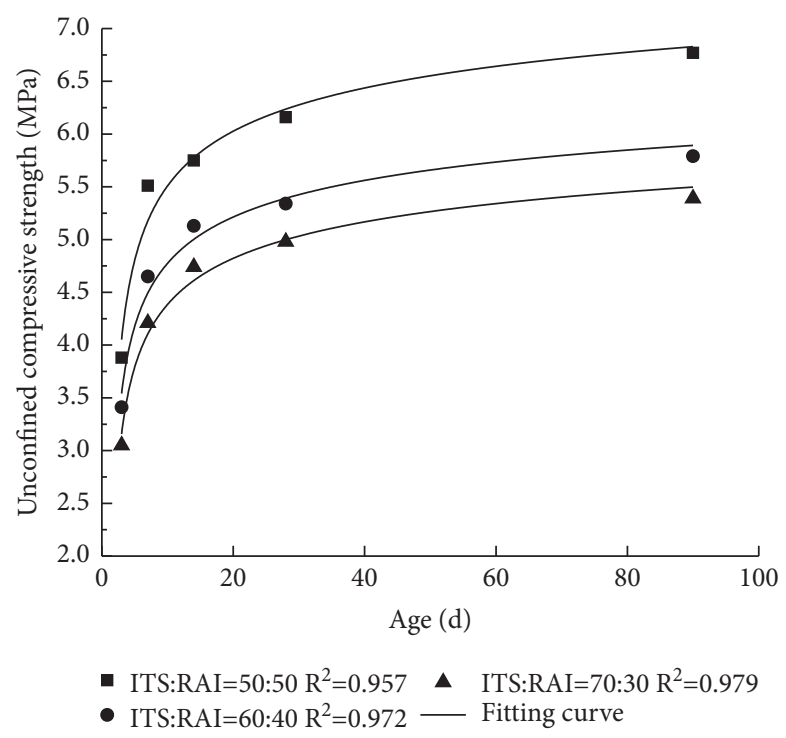

Figure 5: Change rule of compressive strength with ages.

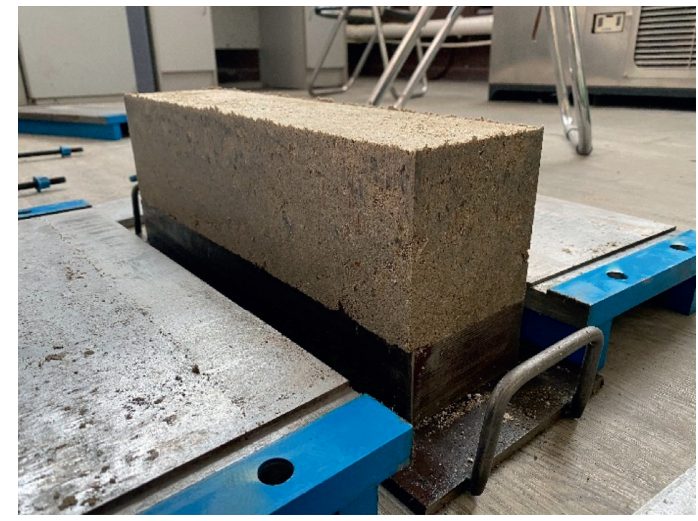

Figure 6: Medium beam specimen.

Specification for Design of Highway Asphalt Pavements (D50-2017), the recycled mixture has good tensile properties.

3.3. Resilient Modulus. Considering the nonlinear elastoplastic properties of soils and granular material [15] and their differences with the traditional elasticity theory, we usually define the ratio of the repetitive stress to the refundable strain after stabilization of deformation under repeated loading as the rebound modulus, which is an important indicator of pavement materials, and an in-depth understanding of the rebound modulus of materials is of great significance to understand the mechanical properties of materials. Guo [16], from Southeast University, conducted an experimental evaluation of compressive strength and compressive rebound modulus (CRM) and concluded the process of unconfined compressive strength test experienced in the process of rebound modulus test. So, they emphasized the importance of compressive rebound modulus to the construction quality control. On the contrary, the real force state of pavement is closer to the flexural-tensile state, so the flexural-tensile rebound modulus (FTRM) also needs to analyze. Concerning the existing approved modulus determination age, the five preferred ratios measured for compressive resilient modulus and flexural-tensile resilient modulus at $90 \mathrm{~d}$. The test results are shown in Table 7.

From the test results, it can be seen that the compressive and flexural-tensile modulus of the recycled mixture increases with the increase of the amount of cementitious material under the same amount of ITS, while it decreases with the increase of ITS under the same amount of cementitious material. Through calculation, the compressive resilient modulus is $2-3$ times of the flexural-tensile resilient modulus, which is similar to cement-stabilized aggregates. According to studies [17, 18], the compressive resilient modulus of cement-stabilized aggregates is close to $10,000 \mathrm{MPa}$ at the same strength level, while the flexuraltensile resilient modulus of the recycled mixture is less than $1 / 3$ of it. Through analysis $[19,20]$, on the one hand, there is relatively high water content in the recycled mixture. The existence of water will "lubricate" the particles and increase elastic deformation. On the other hand, the increase of the fines content leads to the decrease of the rebound modulus of the recycled mixture. However, the lower modulus of the material is beneficial to the crack resistance of the material under the premise of good strength.

\subsection{Compressive Strength and Rebound Modulus Relationship} Establishment. Considering that the unconfined compressive strength is used as the proportional design index during construction, there may not be conditions to determine the rebound modulus of the material, and the modulus is a key factor in the design of the pavement structural layer thickness. So, it is necessary to establish the relationship between compressive strength and rebound modulus for construction reference or as an index for construction quality control. The relationship between $7 \mathrm{~d}$ compressive strength and $90 \mathrm{~d}$ rebound modulus of the recycled mixture 


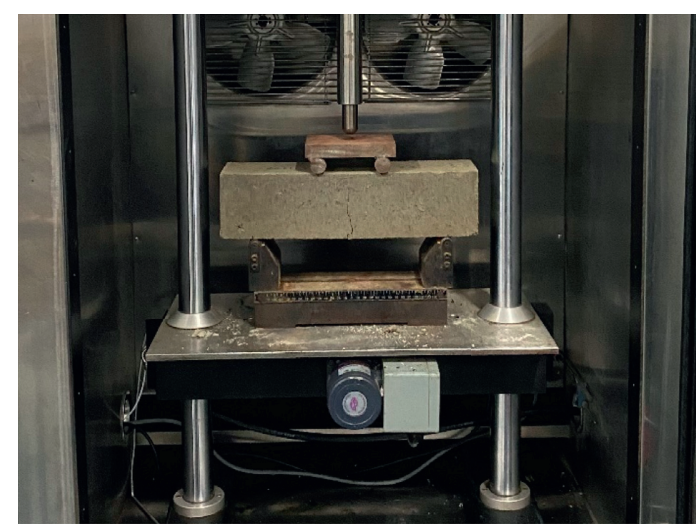

FIgURE 7: Flexural-tensile strength testing.

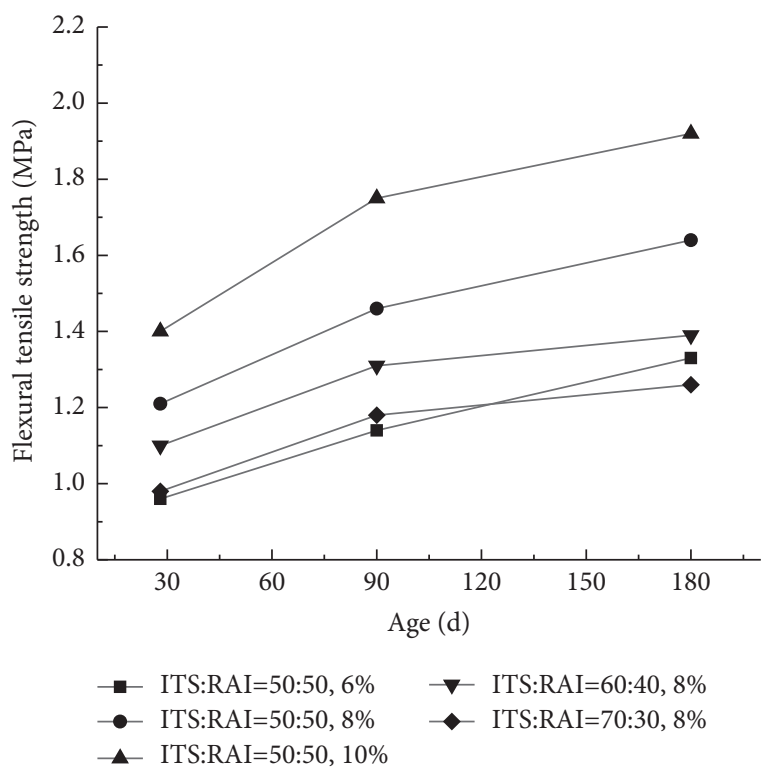

FIgURE 8: Change rule of flexural-tensile strength with ages.

in this study is shown in Figure 9, where FTRM refers to flexural-tensile resilient modulus and CRM refers to compressive resilient modulus.

Regression of the data in Figure 4 and Table 7 yields the equation for the relationship between $7 \mathrm{~d}$ compressive strength and $90 \mathrm{~d}$ rebound modulus; for compressive rebound modulus, $E_{\mathrm{c}}=913 \mathrm{R}_{\mathrm{c}}-68\left(R^{2}=0.976\right)$; for flexuraltensile rebound modulus, $E_{\mathrm{s}}=510 \mathrm{R}_{\mathrm{s}}-517\left(R^{2}=0.909\right)$.

\section{Strength Formation Mechanism}

The micromorphology can reflect the surface structure and crystallization of the material; it can also intuitively and qualitatively evaluate the aggregation characteristic of hydration products such as the morphology or the degree. The hydration product is an important factor affecting the strength characteristic of the material, and the amount is the main measure of the product amount [5]. In this study, SEM and XRD tests are used to compare the surface morphological characteristics and the differences in the dosage of hydration products of the recycled mixtures with different ratios that meet the strength design requirements of highgrade pavement, and the strength formation mechanism of the recycled mixture is explored. And finally, the macrostrength changes rules of the recycled mixture which are compared with the microconclusion.

4.1. Surface Morphology. Taking samples from the specimens with different ratios and different ages after testing and the agglomerated ITS and RAI with the volume of $1 \mathrm{~cm}^{3} \sim 2 \mathrm{~cm}^{3}$ which are immersed in alcohol to terminate the hydration, then the obtained samples and the RAI obtained from pavement milling are dried in an oven at $60^{\circ} \mathrm{C}$ and then SEM tests are conducted. The surface morphology of RAI on recycled mixture and RAI obtained from pavement milling are compared, as shown in Figures 10 and 11, and the agglomerated iron tailing sand results are shown in Figures 12 15. The name of the figures corresponds to the amount of ITS admixture, the amount of cementitious material admixture, the age of the specimen, and the magnification of the test observation and figure, respectively.

From Figure 10, it can be seen that there is a large amount of floating slurry on the surface of RAI obtained from pavement milling. And, compared with Figure 11, the hydration products are in the shape of a net, and this net structure intertwines and bonds the floating slurry on the surface of RAI and then bonds with ITS to form the strength. Combined with Figures 12-15 and based on the existing studies on the mechanism of materials stabilized with inorganic binders $[5,21]$ and the shape of hydration products in microscopic morphology, it is found that the formation of high strength is through the mutual cross-linking of the gel generated by the volcanic ash effect (shown by arrows in the figure) and the pin-rod crystals and block crystals generated by the crystallization effect (shown by rectangular boxes in the figure).

Compared with Figures 12 and 13, it can be seen that the recycled mixture with $50 \%$ ITS admixture already has a large number of needle-rod crystals at the age of 7 days. And, they are considered to be the main reason for the early strength formation through its intersection with the gel. At the age of 28 days, the number of needle-stick crystals increased, but it can be seen from the tops of the needle-stick crystals (elliptical box in Figure 8), and they developed radially but more slowly. So, it is believed that the strength of the recycled mixture from $7 \mathrm{~d}$ to $28 \mathrm{~d}$ in the continued growth, but the trend is relatively slow, and it also verifies the conclusion of the macroscopic test that strength formation is slower after $7 \mathrm{~d}$. Compared with Figures 13 and 14, it can be seen that when the amount of cementitious material increased to $8 \%$, the number of needle-rod crystals increases significantly, and a large number of block crystals generated, and they are intertwined together to form a network skeleton, which is conducive to promoting the formation of the strength of the recycled mixture, so it is believed that the higher the amount of cementitious material under the same iron tailings sand admixture is, the better the mechanical properties of the recycled mixture are. 
TABLE 7: Resilient modulus results.

\begin{tabular}{lccccc}
\hline $\begin{array}{l}\text { ITS content } \\
(\%)\end{array}$ & $\begin{array}{c}\text { RAI content } \\
(\%)\end{array}$ & $\begin{array}{c}\text { Cementitious material } \\
\text { content }(\%)\end{array}$ & $\begin{array}{c}\text { Ages } \\
(\mathrm{d})\end{array}$ & $\begin{array}{c}\text { Compressive resilient modulus } \\
(\mathrm{MPa})\end{array}$ & $\begin{array}{c}\text { Flexural-tensile resilient } \\
\text { modulus }(\mathrm{MPa})\end{array}$ \\
\hline 50 & 50 & 6 & & 4177 & 1758 \\
50 & 50 & 8 & & 5057 & 2325 \\
50 & 50 & 10 & 90 & 6300 & 3010 \\
60 & 40 & 8 & & 3960 & 2105 \\
70 & 30 & 8 & 3904 & 1488 \\
\hline
\end{tabular}

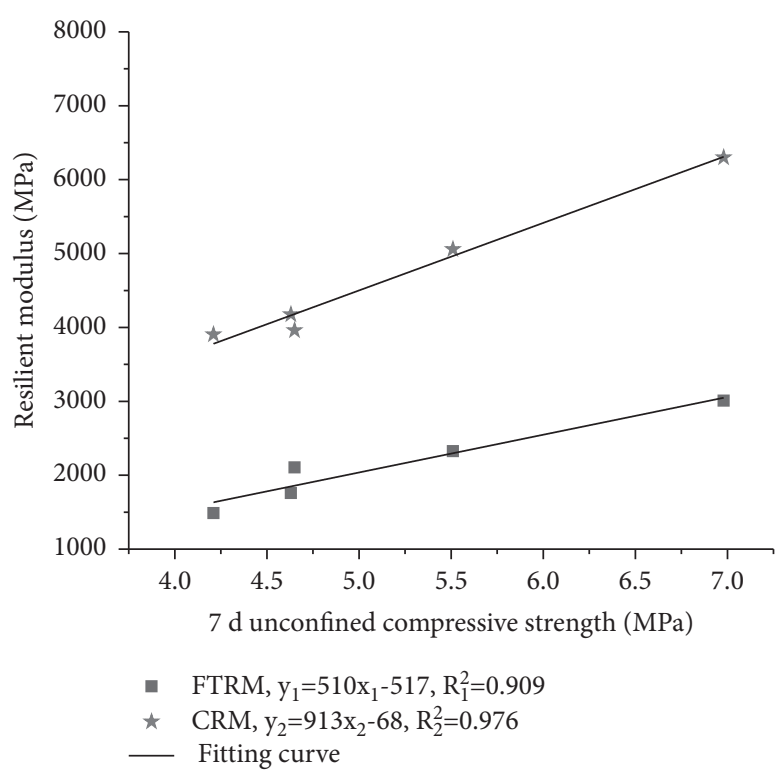

Figure 9: Relationship between compressive strength and resilient modulus.

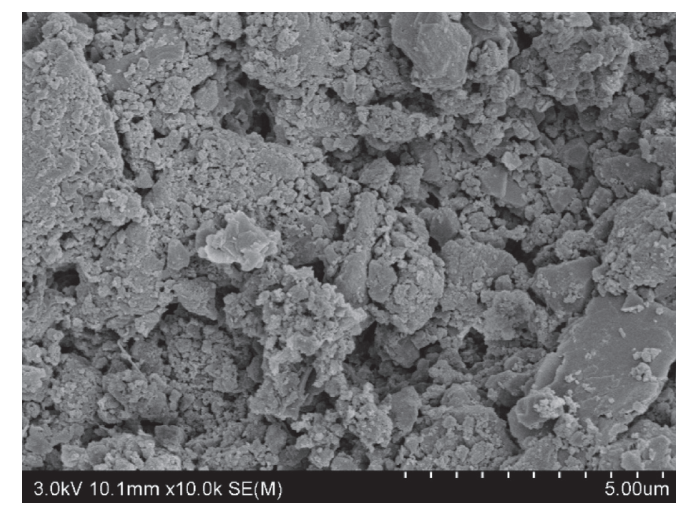

Figure 10: RAI from pavement milling.

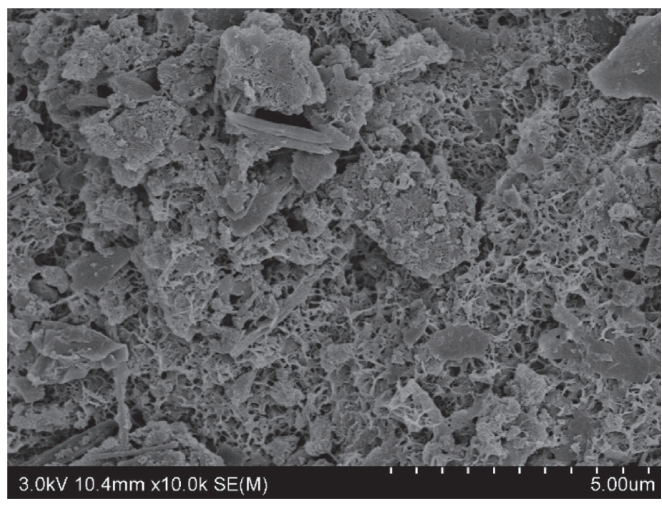

FIGURE 11: RAI from recycled mixture. 


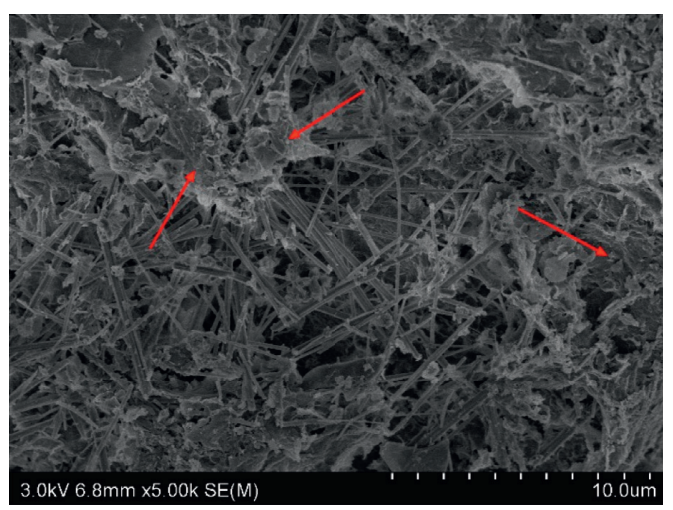

Figure 12: 50\%, 6\%, $7 \mathrm{~d}$, and 5000 .

Figure 15 shows the apparent morphology at the age of 7 days with $70 \%$ of ITS and $8 \%$ of cementitious material, which is magnified 10,000 times. It is found that the degree of crystallization is low at this time, compared with the formation of embedded cross-linking in Figure 14; a few crystals are connecting a large number of gels to form strength. So, it is believed that the higher the content of ITS with the same cementitious material, the worse the mechanical properties of the recycled mixture, and it also verifies the macroconclusions.

4.2. Analysis of Hydration Products. Taking samples from the specimens with different ratios and different ages after testing, the samples are dried after terminating hydration, ground into powder, and passed through $0.075 \mathrm{~mm}$ sieve. And, the lower part of the sieve is taken for compositional analysis, and the test incidence angle is selected from 5 to $75^{\circ}$ wide range for detection, and the scanning rate is $5^{\circ} / \mathrm{min}$. The Origin software is used to process the characteristic peaks (hydration products), and the processing results are shown in Figures 16 and 17.

Figure 16 compares the characteristic peaks of the age of 7 days with $6 \%$ and $8 \%$ of cementitious material at $50 \%$ of ITS content and finds that the characteristic peaks basically overlap, and only the peaks differ significantly, which means that the difference in hydration product types is not significant while the degree of hydration is different. Figure 17 compared the characteristic peaks of the age of 7 days with $50 \%$ and $70 \%$ of ITS content at $8 \%$ of cementitious material. In comparison with Figure 16, it is found that the overlap of the characteristic peaks of the two recycled mixtures in Figure 17 is lower and the peak difference is larger, so it is believed that there is a large difference between the hydration products and the degree of hydration at this stage, which is consistent with the SEM test results. And, except for the characteristic peak maximum, the other peak strength differences are low, so the characteristic peak maximum strength is considered to be the main factor affecting the performance of the recycled mixture.

At the same curing age, the maximum characteristic peak strength of $6 \%$ of cementitious material with $50 \%$ of ITS is 2694 pcs, 345 pcs smaller than 3048 pcs with $8 \%$ of cementitious material. It means the cementitious material content increased by $2 \%$, and the character peak strength of recycled mixture increases about $13 \%$. The character peak strength of ITS content at $70 \%$ with $8 \%$ of cementitious material is 2365 pcs, which is 683 pcs smaller than 3048 pcs at $50 \%$, which means the ITS content increases by $20 \%$, the character peak strength of recycled mixture reduced about $22 \%$, which corresponds with flexural-tensile strength data from macrotests. Through analysis, the performance of the recycled mixture becomes stronger with the increase of cementitious materials content and becomes weaker with the increase of ITS content, and the degree of influence of cementitious materials is greater, which further verifies the macroconclusions.

\section{Environmental and Economic Benefits}

At present, China is the world's largest greenhouse gas emissions while green low-carbon is an important part of the new development concept; if the recycled mixture $100 \%$ replacement of cement-stabilized aggregates is applied to the pavement, it not only helps to solve the problem of iron tailings sand stockpile and reduce construction costs but also reduces carbon emissions.

5.1. Environmental Benefits. According to the PBL (Planetary Boundary Layer) Norwegian EIA (Ecological Impact Assessment), global greenhouse gas emissions in 2018 were about 55.6 billion tons of carbon dioxide equivalent, of which China accounted for $26 \%$. The carbon emissions will reduce in the gravel mining and processing process if the recycled mixture replaces the traditional cement-stabilized aggregates base course materials, which can promote the decarbonization process of the world. Consider the large variability of transportation distance, and this study does not consider the carbon emission difference generated in the transportation process.

According to the field research, the energy consumption of stone in mining process $p_{11}$ is about $1.1 \mathrm{~kg} / t$, and the energy consumption of processing process $p_{12}$ is about $0.12 \mathrm{~kg} / t$, where the energy consumption is all in diesel. According to the General Principles for Calculation of Total Production Energy Consumption GB/T2589-2008, the formula for calculating comprehensive energy consumption is shown as

$$
E=\sum_{1}^{n}\left(e_{i} \times p_{i}\right),
$$

where $E$ denotes comprehensive energy consumption, $n$ denotes the number of energy species consumed, $e_{i}$ denotes the $i$ th energy substance consumed in production, and $p_{i}$ denotes the conversion factor of the $i$ th energy.

In this study, $e_{i}$ only calculates aggregates, so the energy saving is $\Delta E=e_{11} \times p_{11}+e_{12} \times p_{12}$. If the average width of the base course is $15 \mathrm{~m}$ and thickness is $0.2 \mathrm{~m}$, it is expected that the recycled mixture can be consumed about 7000 tons per kilometer, so the energy saving of diesel per kilometer is $8540 \mathrm{~kg}$. According to the General Principles for Calculation of Total Production Energy Consumption, the coal 


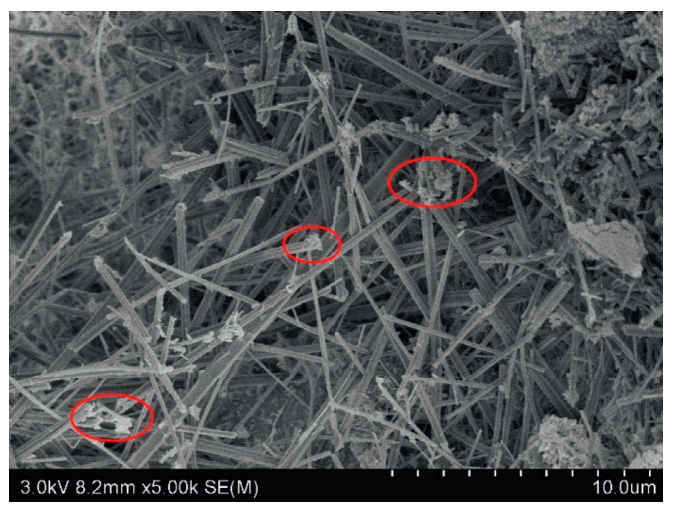

Figure 13: 50\%, 6\%, $28 \mathrm{~d}$, and 5000.

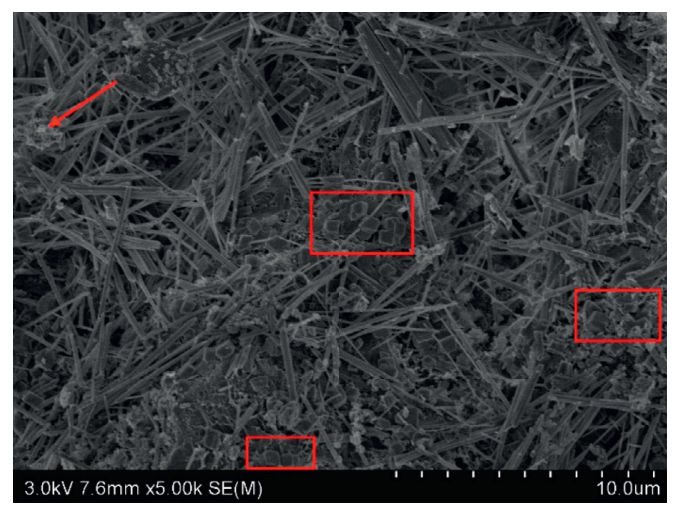

Figure 14: 50\%, 8\%, $7 \mathrm{~d}$, and 5000.

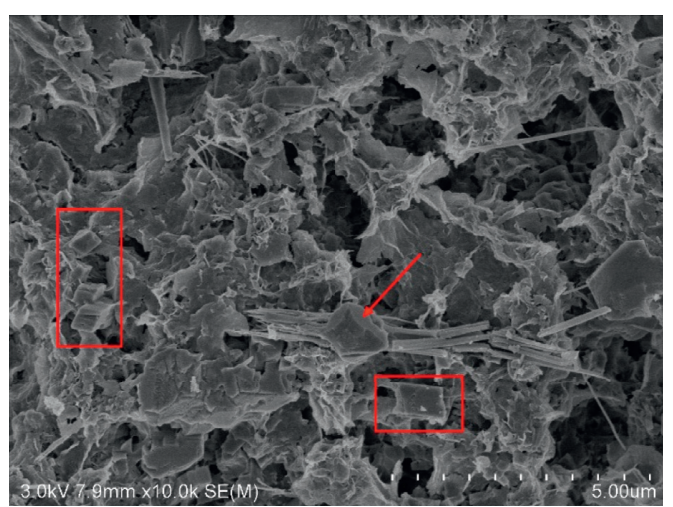

Figure 15: 70\%, 8\%, $7 \mathrm{~d}$, and 10000.

conversion factor of diesel fuel is $1.4571 \mathrm{kgce} / \mathrm{kg}$, and the $\mathrm{CO}_{2}$ emission factor is $3.0959 \mathrm{~kg}-\mathrm{CO}_{2} / \mathrm{kg}$. The calculated energy saving of recycled mixture per kilometer is 12.45 tce, and the carbon reduction is $26.44 \mathrm{tCO}_{2}$.

5.2. Economic Benefits. If the average width of the base course is $15 \mathrm{~m}$ and thickness is $0.2 \mathrm{~m}$, it is expected that each kilometer can consume about 7000 tons of recycled mixture. If the mixing ratio of the recycled mixture is considered as ITS: $\mathrm{RAI}=70 \%: 30 \%$, each kilometer will consume nearly 5000 tons of ITS and 2000 tons of RAI. In terms of social

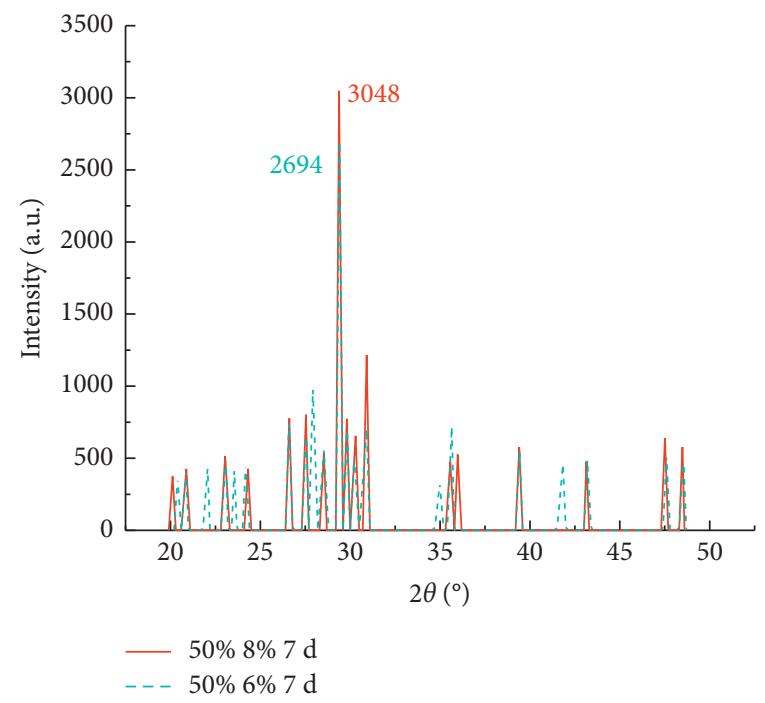

Figure 16: Peak comparison 1.

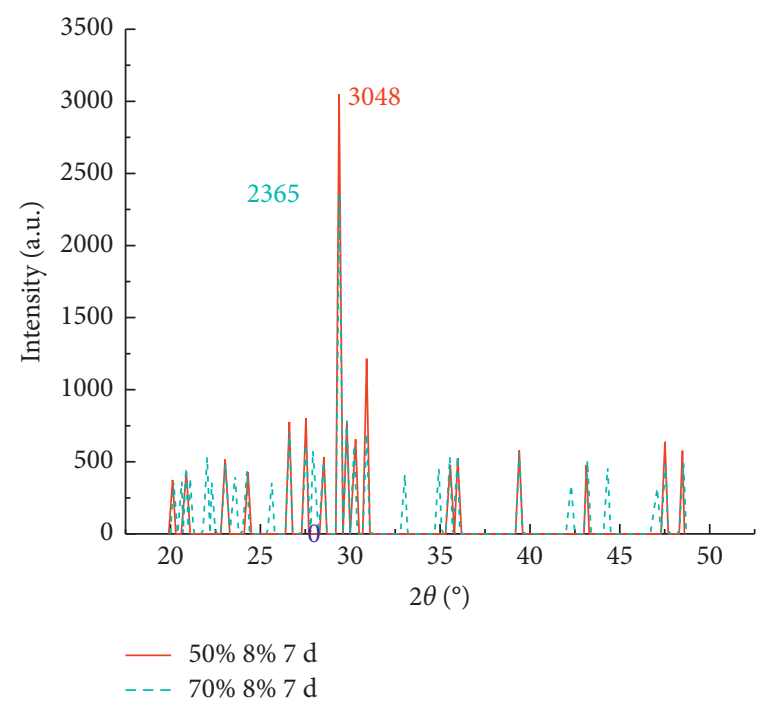

Figure 17: Peak comparison 2.

costs, according to the price of treatment in the backing project (Shanxi Province), it is assumed that the disposal fee of ITS is 30 yuan per ton and the disposal fee of RAI is 20 yuan per ton, and each kilometer will save nearly 200,000 $\mathrm{RMB}$. In terms of construction costs, according to the aggregates price in the backing project (Shanxi Province), it is assumed that the cement-stabilized aggregates are 100-150 $\mathrm{RMB}$ per ton and the recycled mixture is $50-100 \mathrm{RMB}$ per ton, which will save at least 350,000 RMB per kilometer of construction capital.

\section{Conclusions}

(1) Results of laboratory tests show that the recycled mixture has excellent mechanical properties; the material strength is more affected by the content of cementitious materials. In addition, the recycled 
mixture also can meet the strength requirements of the base course on the various grades of pavement by adjusting the material composition.

(2) Results of SEM and XRD test show that the strength of recycled mixtures are mainly formed by filling the internal space of the mixture with gels and crystals of hydration products and cross-linking each other to stabilize the surrounding scattered particles.

(3) The relationship between $7 \mathrm{~d}$ compressive strength and rebound modulus is established by linear regression analysis; for compressive rebound modulus, $E_{\mathrm{c}}=913 \mathrm{R}_{\mathrm{c}}-68 \quad\left(R^{2}=0.976\right)$; for flexural-tensile rebound modulus, $E_{\mathrm{s}}=510 \mathrm{R}_{\mathrm{s}}-517\left(R^{2}=0.909\right)$.

(4) The "ITS plus RAI" solid waste treatment method proposed in this paper can effectively reduce carbon emissions from stone mining and processing and save construction costs. The engineering application in Shanxi province shows that the average energy saving per kilometer is about 12.45 tce and carbon reduction is about $26.44 \mathrm{t}$ of $\mathrm{CO}_{2}$. In terms of social costs, it will save nearly 200,000 RMB per kilometer, and in terms of construction costs, it will save at least 350,000 RMB per kilometer, which has great social and economic benefits.

This paper only studied the mechanical properties of the recycled mixture, and further research is needed on the pavement performance such as shrinkage and fatigue characteristics.

\section{Data Availability}

The data used to support the findings of this study are included within the article.

\section{Conflicts of Interest}

The authors declare that they have no conflicts of interest.

\section{Acknowledgments}

The authors thank China Highway Engineering Consulting Corporation for their support.

\section{References}

[1] A Liu, M Cao, and X Zhang, "The research status of large-scale utilization of iron tailings and its utilization methods," Chinese Metal Bulletin, vol. 11, pp. 279-280, 2019.

[2] H. Li, "Research on the influence of iron tailings on the performance of cement stabilized crushed stone base course," Highway, vol. 12, 2014.

[3] B. F. Pan, H. Yu Shi, and C. H. Zhou, "Experimental research on shrinkage properties of cement stabilized iron tailings sand mixture," Applied Mechanics and Materials, vol. 423, 2013.

[4] H. Song, H. Feng, and Z. Pan, "Analysis of design parameters of curing agent stabilized iron tailing base structure," Shanghai Highway, vol. 3, pp. 69-72+101, 2020.

[5] W. Jiang, Research on the Strength Mechanism of Inorganic Binder Iron Tailings and the Optimization Design Application to the Base Layer, Harbin Institute of Technology, Heilongjiang, China, 2018.

[6] Q. Bai, H. Zhang, and W. Bao, "Experimental study on stabilization of iron tailings sand gravel by inorganic binding material," Urban Roads and Bridges and Hong, vol. 4, pp. 159-161+171+22, 2020.

[7] D. Xue, "The application of iron tailings sand in the waterstable gravel base of national and provincial trunk roads," Shandong Communications Science and Technology, vol. 6, pp. 46-48+64, 2020.

[8] S. Lu, P. Jiang, B. Qian, W. Wang, and N. Li, "Research progress on mechanical properties and recycling of iron tailings sand," Bulletin of the Chinese Ceramic Society, vol. 39, no. 2, pp. 466-470+512, 2020.

[9] X. Niu and Y. Sun, "Numerical analysis on settlement and stability of iron ore tailings subgrade," Journal of Chang'an University (Natural Science Edition), vol. 38, no. 1, pp. 9-16, 2018.

[10] R. Hou, S. Chen, and M Xiao, "Study on the mechanical properties of iron tailing sand cement composite soil," China \& Foreign Highway, vol. 39, no. 1, pp. 206-209, 2019.

[11] L. Fu, Study on Strengthening Treatment and Application of Cement Stabilized Aggregate Milling Material, Shandong University of Technology, Shandong, China, 2019.

[12] Z. Ma, H. Li, and Y. Lu, "Study on the properties and grading influencing factors of cement in-situ cold recycled base milling material," China \& Foreign Highway, vol. 38, no. 2, pp. 263-268, 2018.

[13] W. Gu, P. Xiao, and Y. Yang, "Experimental study on shrinkage and fatigue properties of recycled cement stabilized crushed stone base materials," Concrete and Cement Products, vol. 12, pp. 95-100, 2018.

[14] Q. Bai, H. Zhang, and W. Bao, "Study on the road performance of solidified iron tailings," Hunan Transportation Science and Technology, vol. 46, no. 3, pp. 40-43+47, 2020.

[15] X. Yan, C. Liang, J. Xu, Y. Q. long, and A. Li, "Elastoplastic of characteristics cement-stabilized aggregate bases," China Journal of Highway and Transport, vol. 32, no. 1, pp. 29-36, 2019.

[16] G. Guo, J. Wang, and C. Fei, "A study on relationship between unconfined compressive strength and compression rebound modulus of cement stabilized aggregate," Highway, vol. 1, pp. 171-174, 2007.

[17] P. Zhang, Research on Anti-cracking Performance of Semi-rigid Base Course in High-Grad Highway, Dalian University of Technology, China, Liaoning, 2007.

[18] A. Sha and L. Hu, "Structural characteristics of semi-rigid base course material," China Journal of Highway and Transport, vol. 4, pp. 1-5+42, 2008.

[19] N. H. Thom and S. F. Brown, Effect of Moisture on the Structural Performance of a Crushed-Limestone Road Base, Transportation Research Record, Nottingham, England, 1987.

[20] R. Hicks and C. Monismith, "Factors influencing the resilient response of granular materials," Highway Research Record, vol. 345, pp. 15-31, 1971.

[21] M. Dong, T. Ling, and J. Xu, "Mechanism on the phosphogypsum-improved semi-rigid basecourse," China Journal of Highway and Transport, vol. 2, pp. 14-18, 2002. 